\title{
Chl $a$ fluorescence and proteomics reveal protection of the photosynthetic apparatus to dehydration in tolerant but not in susceptible wheat cultivars
}

\author{
M. NYKIEL ${ }^{1}$, P. LISIK ${ }^{1}$, J. DĘBSKI ${ }^{2}$, B. FLOREA ${ }^{3}$, and K. RYBKA ${ }^{4 *}$ \\ Department of Biochemistry, Warsaw University of Life Sciences, PL - 02776 Warsaw, Poland ${ }^{1}$ \\ Institute of Biochemistry and Biophysics, IBB-PAN, PL - 02106 Warsaw, Poland ${ }^{2}$ \\ Leiden Institute for Chemistry, NL-2333CC Leiden, the Netherlands ${ }^{3}$ \\ Plant Breeding and Acclimatization Institute - National Research Institute, Radzików, PL -05870 Btonie, Poland ${ }^{4}$
}

\begin{abstract}
Seedlings of spring wheat (Triticum aestivum L.) cultivars, Ethos and Zebra, differing in drought tolerance were dehydrated to reach a water saturation deficit (WSD) in leaves $\sim 15,30$, and $50 \%$. Ethos, the drought tolerant cultivar, dried slower in comparison with Zebra and regrew in $70 \%$ upon rehydration. The effect of dehydration on photosystem II was evaluated by $\mathrm{Chl} a$ fluorescence (OJIP transients). The inflection point of double normalized curves $\left(\Delta \mathrm{W}_{\mathrm{OJ}}\right)$ calculated for Ethos was negative for seedlings with $15 \%$ WSD, nearly zero for those with $30 \%$ WSD, and about +0.05 for those with $50 \%$ WSD. In case of Zebra, the $15 \%$ WSD already induced a positive $\Delta \mathrm{W}_{\mathrm{OJ}}(+0.05)$ and $50 \%$ WSD maximized it to +0.10 , which is a sign of drought susceptibility. The proteomic studies revealed, that among identified 850 spots, 80 protein spots were differentially expressed during dehydration. The differentially expressed proteins of the drought tolerant cultivar indicated the protection of the photosynthetic apparatus and proteome rebuilding in response to drought. In the drought susceptible cultivar, protection of proteins and membranes and partial scavenging reactive oxygen species appeared.
\end{abstract}

Additional key words: 2D electrophoresis, drought, Kautsky effect, OJIP, polyphasic fluorescence transient, Triticum aestivum.

\section{Introduction}

Wheat is among the most important food grains. It is mostly cultivated in areas with annual precipitations in the range of $375-875 \mathrm{~mm}$ (Curtis 2002). Temporary soil water deficit extended to chronic drought can occur due to weather fluctuations also in areas with an optimal climate. If it happens during one of the critical stages of plant development, such as booting, anthesis, or grain filling, it may result in irreversible anatomical changes: a lower number of bud spikelets, pollen sterility, or poorly formed grains (Grudkowska et al. 2003; Semenov et al. 2014). In regions, such as Central Europe, spring cultivars are additionally subjected to spring drought, which inhibits tillering and can result in a lower number of shoots per plant and a slower canopy formation (Blum 2011, Rybka and Nita 2014).

According to Levitt (1980), abiotic stresses including drought may induce three types of plant response: escaping, avoidance, or tolerance. Escaping can be described as vegetation beyond the time of stress duration, avoidance slowing down life processes, whereas tolerance is a metabolic switch to adapt to unfavorable conditions. According to many authors, effective drought resistance in crop plants is largely achieved by dehydration avoidance in the way of maintaining the leaf pressure potential by partial closing stomata and/or by increasing water uptake by roots (Blum 2011).

Submitted 20 March 2018, last revision 28 September 2018, accepted 8 October 2018.

Abbreviations: Chl $a$ - chlorophyll a; ETC - electron transfer chain; IEF - isoelectric focusing; LC-MS-MS/MS- liquid chromatography coupled to tandem mass spectrometry; $\mathrm{O}_{2}{ }^{--}$superoxide radicals; OJIP - point of inflection on fluorescence transient; PS II - photosystem II; RC/ABS - amount of active reaction centers per absorption; ROS - reactive oxygen species; WSD - water saturation deficit; $\Delta \mathrm{W}_{\mathrm{OJ}}$ - curves of double normalized fluorescence data, revealing the $\mathrm{K}$ inflection point.

Acknowledgments: This work was partially financed by grants from the National Science Center of Poland NN310079839 and NN304267540. The authors thank Prof. Jan Rybczyński, Center for Biological Diversity Conservation at Botanical Garden, Polish Academy of Sciences, Powsin, Poland, for allowing the gels scanning.

* Author for correspondence; e-mail: k.rybka@ihar.edu.pl 
Depending on the genotype, plants either react rapidly by rebuilding the cell machinery in expense of significant energy demand or more slowly using lower energy inputs (Voss et al. 2013, Noctor et al. 2014). Commercial cultivars should be resistant and good yielding not only during an optimal season but also during a dry summer. This difficult selection task requires solutions by delicate methodological approaches.

The OJIP test is based on chlorophyll $a(\mathrm{Chl} a)$ fluorescence, a natural phenomenon characteristic for all photosynthetic organisms. The analysis of fluorescence data allows evaluate the efficiency of photochemical reactions and indirectly the whole metabolism (Goltsev et al. 2016).

Proteomic data interpretation is mostly oriented towards current concepts of stress tolerance, which is focused on reactive oxygen species (ROS) mainly generated in photosynthetic tissues by chloroplasts, mitochondria, and peroxisomes (Miller et at. 2010). A major ROS, the superoxide radical $\left(\mathrm{O}_{2}{ }^{-}\right)$, is formed as a result of 'electron leakage' in the electron transfer chains (ETCs) of chloroplasts (Miller et al. 2010, Demidchik 2015) and mitochondria (Moller 2001) and in

\section{Materials and methods}

Plants and treatments: Four sets of 25 just germinated grains of spring wheat (Triticum aestivum L.) cvs. Ethos and Zebra differing in drought resistance were placed side by side between double filter paper strips moistened with a Knopp solution supplemented with Hoagland micronutrients (Grudkowska and Zagdanska 2010), rolled up, and grown for $11 \mathrm{~d}$ in plastic boxes in a climate chamber with day/night temperatures of $18 / 14^{\circ} \mathrm{C}$, a $16-\mathrm{h}$ photoperiod, a photosynthetic photon flux density (PPFD) of $260 \mu \mathrm{mol} \mathrm{m} \mathrm{m}^{-2} \mathrm{~s}^{-1}$, and an air humidity of $70-$ $80 \%$. To induce dehydration, the nutrient solution was drained for 24 - $96 \mathrm{~h}$. The water saturation deficit (WSD) in leaves was determined gravimetrically as described in details by Miazek et al. (2017). Fully rigid, control seedlings and seedlings having WSD of 15, 30, and $50 \%$ were used for following studies.

Chlorophyll $\boldsymbol{a}$ fluorescence transient curves were measured on dark adapted $(0.5 \mathrm{~h})$ leaves using a Pocket PeA portable fluorometer (Hansatech Instruments, King's Lynn, Norfolk, UK). Fluorescence from the adaxial surface was induced by saturating light of $3500 \mu \mathrm{mol} \mathrm{m} \mathrm{m}^{-2}$ $\mathrm{s}^{-1}$, and transient fluorescence for first $3 \mathrm{~s}$ was registered with time intervals increasing from $10 \mu$ s during first 300 $\mu \mathrm{s}$ of the measurement up to $100 \mathrm{~ms}$ intervals for time longer than $0.3 \mathrm{~s}$. A list of measured parameters included: $\mathrm{F}_{0}$ (minimum fluorescence measured at $0.05 \mathrm{~ms}$ ), $\mathrm{F}_{1}, \mathrm{~F}_{2}$, $\mathrm{F}_{3}, \mathrm{~F}_{4}$, and $\mathrm{F}_{5}$ (fluorescence at times: 0.05, 01, 03, 2.0, and $30 \mathrm{~ms}$ ) followed by $\mathrm{F}_{\mathrm{M}}$ (maximum fluorescence at about $300 \mathrm{~ms}$ after the onset of light). Values at 0.3, 2.0, peroxisomes by the glycolate-glyoxylate shuttle (Noctor et al. 2014). The $\mathrm{O}_{2}{ }^{-}$half-life is short $(1-1000 \mu \mathrm{s})$, thus it cannot noticeably damage the cell macromolecules, however, $\mathrm{H}_{2} \mathrm{O}_{2}$ formed on a way of $\mathrm{O}_{2}{ }^{-}$scavenging by superoxide dismutases is harmful. The organelles of mesophyll cells generate $\mathrm{H}_{2} \mathrm{O}_{2}$ as an integral part of $\mathrm{C}_{3}$ photosynthesis: under optimal conditions about 10000 nmol m$~^{-2} \mathrm{~s}^{-1}$ in peroxisomes, 4030 in chloroplasts, and $<$ 400 in mitochondria (Foyer and Noctor 2003). Much attention was paid to mechanisms of ROS scavenging by antioxidant enzymes and non-enzymatic antioxidants (Foyer and Noctor 2011, Jogaiah et al. 2013, Kopczewski and Kuźniak 2013, Noctor et al. 2014), whereas less to the thermodynamic balance of biochemical reactions induced by stress (Marín et al. 2014, Igamberdiev 2015).

Materials used for the studies were commercial cultivars, which differ in physiological and biochemical responses to dehydration stress. The aim of this article was to analyze Chl $a$ fluorescence using OJIP test (Strasser et al. 1995, Stirbet and Govindjee 2011) along with a detailed interpretation of proteomic data. The conclusions could help in planning future breeding programs. and $30 \mathrm{~ms}$ respond to fluorescence at $\mathrm{K}$, J, and I points of inflections on a fluorescence transient curve. The $F_{M}=F_{P}$ is a maximal recorded fluorescence; $\mathrm{t}_{\mathrm{FM}}$ is a time in [ms] to reach the maximal fluorescence; Area is a total complementary area between the fluorescence induction curve and $\mathrm{F}_{\mathrm{M}}$ of the OJIP curve. A list of parameters calculated by the Pocket PeA software included: variable fluorescence $\left(\mathrm{F}_{\mathrm{V}}=\mathrm{F}_{\mathrm{M}}-\mathrm{F}_{0}\right)$; the maximum quantum yield of primary photochemistry $\mathrm{F}_{\mathrm{V}} / \mathrm{F}_{\mathrm{M}}$; the amount of active reaction centers per absorption, which is the reciprocal value of the antenna size for photosystem (PS) II $\mathrm{RC} / \mathrm{ABS}$; the measure of forward electron transport (1$\left.\mathrm{V}_{\mathrm{J}}\right) / \mathrm{V}_{\mathrm{J}}$, where $\mathrm{Vj}=\mathrm{V}_{\mathrm{J}}$ is a fluorescence value at $2 \mathrm{~ms}$; and the performance index of PS II based on absorption ( $\mathrm{PI}_{\mathrm{ABS}}$ ) (Paunov et al. 2018). Significance of differences were determined by the $t$-test $(\alpha=0.05)$. Additionally, collected data points were double normalized between points O-J, and the kinetic differences $\Delta \mathrm{W}_{\mathrm{OJ}}$ were calculated and analyzed as graphs on the logarithmic time-scale (Oukarroum et al. 2007, Żurek et al. 2014).

Proteomics: Total soluble proteins were extracted and cleaned up using a modified phenol procedure (Wang et al. 2006). About $200 \mathrm{mg}$ of fresh tissue was ground in liquid nitrogen to a whitish powder, placed in an Eppendorf tube and mixed with $1.5 \mathrm{~cm}^{3}$ of $10 \%(\mathrm{~m} / \mathrm{v})$ trichloroacetic acid in acetone to precipitate proteins. After $30 \mathrm{~min}$ at $-20^{\circ} \mathrm{C}$, the samples were centrifuged at $16000 \mathrm{~g}$ and $4{ }^{\circ} \mathrm{C}$ for another $30 \mathrm{~min}$. The supernatant was poured out, and the pellet was rinsed twice: first with 
$0.1 \mathrm{M}$ ammonium acetate in $80 \%(\mathrm{v} / \mathrm{v})$ methanol and then with an ice cold $80 \%(\mathrm{v} / \mathrm{v})$ acetone, both followed by centrifugation $\left(12000 \mathrm{~g}, 4^{\circ} \mathrm{C}, 30 \mathrm{~min}\right)$. The resulting pellet was dried in a vacuum centrifuge for $5 \mathrm{~min}$ and resuspended in $0.6 \mathrm{~cm}^{3}$ of SDS buffer [30\% (m/v) glucose, $2 \%(\mathrm{~m} / \mathrm{v})$ SDS, $0.1 \mathrm{M}$ Tris-HCl, $\mathrm{pH} 8.0,5 \%(\mathrm{v} / \mathrm{v})$ 2-mercaptoethanol], from which proteins were extracted with $0.6 \mathrm{~cm}^{3}$ of phenol saturated with Tris- $\mathrm{HCl}(\mathrm{pH} \mathrm{8.0)}$ within $5 \mathrm{~min}$ at room temperature. After centrifugation, the upper phenol phase was collected, transferred into a new tube to precipitate proteins with 5 volumes of $0.1 \mathrm{M}$ ammonium acetate in methanol, at $-20{ }^{\circ} \mathrm{C}$, overnight. After centrifugation $\left(12000 \mathrm{~g}, 4{ }^{\circ} \mathrm{C}, 30 \mathrm{~min}\right)$, the pellet was washed once with an ice-cold methanol and twice with an ice-cold $80 \%$ acetone, air dried, and kept at $-20{ }^{\circ} \mathrm{C}$ until use.

Two-dimensional electrophoresis: Prior to isoelectric focusing, protein samples were dissolved in a rehydration buffer [7 M urea, $2 \mathrm{M}$ thiourea, $2 \%(\mathrm{~m} / \mathrm{v})$ 3-cholamidopropyl-dimethylammonio-1-propanesulfonate (CHAPS), $2 \%(\mathrm{~m} / \mathrm{v})$ carrier ampholytes (pI 3 - 10, Bio-Lytes, BioRad, Hercules, USA), $1 \%(\mathrm{~m} / \mathrm{v})$ DTT]. Protein content was determined spectrophotometrically at $595 \mathrm{~nm}$ by Bradford method with bovine serum albumin as a standard. Solutions of $180 \mu \mathrm{g}$ of proteins in $0.18 \mathrm{~cm}^{3}$ of rehydration buffer were used for passive rehydration of immobilized $\mathrm{pH}$ gradient (IPG) strips (Bio-Rad, $11 \mathrm{~cm}$ length, $4-7 \mathrm{pI}$ ) for $16 \mathrm{~h}$ at room temperature. Isoelectric focusing (IEF) was ran using a Biorad PROTEAN IEF focusing chamber powered for $20 \mathrm{~min}$ by $50 \mu \mathrm{A} /$ strip and $250 \mathrm{~V}$ direct current (DC) and next by $2.5 \mathrm{~h}$ at a linearly increasing voltage up to $8000 \mathrm{~V}$ maintained to achieve final IEF of 20000 volt-hours (Vh). After IEF, the strips were frozen, and the next day equilibrated in an $50 \mathrm{mM}$ Tris- $\mathrm{HCl}$ incubation buffer, $\mathrm{pH} 6.8$, containing $4 \mathrm{M}$ urea, $30 \%(\mathrm{v} / \mathrm{v})$ glycerol, and $2 \%(\mathrm{~m} / \mathrm{v}) \mathrm{SDS}$ for $15 \mathrm{~min}$. After equilibration, the strips were sealed on the top of $10 \%$ $(\mathrm{m} / \mathrm{v})$ SDS-PAGE gels, $15 \times 19 \times 0.1 \mathrm{~cm}$, using $0.5 \%$ $(\mathrm{m} / \mathrm{v})$ agarose in $0.1 \mathrm{M}$ Tris- $\mathrm{HCl}, \mathrm{pH} 6.8$, containing $0.001 \%(\mathrm{~m} / \mathrm{v})$ bromophenol blue. The SDS-PAGE was run in a $50 \mathrm{mM}$ Tris- $\mathrm{HCl}$ buffer at $50 \mathrm{~mA} / \mathrm{gel}$ for about $4 \mathrm{~h}$ until the blue dye front reached the bottom of the gel. The gels were stained in colloid Comassie Brilant blue. A molecular mass standard PageRuler ${ }^{\mathrm{TM}}$ (Thermo Fisher Scientific, Waltham, MA, USA) was used for electrophoresis in the second dimension (Gietler et al. 2016). Four gels, one from each independent biological replication, were used for identification of differential proteins.

Identification of differential proteins: Stained gels were scanned with an ImageScanner III (GE Healthcare, Chicago, USA). The digitalized gels were analyzed using the 2D gel analysis software Delta2D v. 2.0 (Decodon, Greifswald, Germany). Spot volumes were calculated from the sum of the gray values of all pixels within a spot boundary using a hybrid between image segmentation and model-based quantitation (Berth et al. 2007). After image warping (correction of the positional spot variations), a fused image was created as a virtual PC-generated gel image (condensation of the information of all images into one artificial image), followed by the detection of a consensus spot pattern. For spot quantitation, this spot pattern was applied to all gel images of the experiment, and normalized spot volumes were yielded by relating the single spot volume to the total spot volume of all detected spots in the gel image. Accuracy of gel identity among biological replications was evaluated by principal component analysis (Fig. 1 Suppl.). Selection of proteins was based on at least a twofold amount difference evaluated by the $t$-test $(\alpha=0.001)$ (Gietler et al. 2016).

Mass spectrometry characterization of proteins: Peptide mixtures were analyzed by liquid chromatography coupled to tandem mass spectrometry (LC-MS$\mathrm{MS} / \mathrm{MS}$ ) with classic mass spectrometer and LTQ (linear trap quadrupole ion trap - Orbitrap) (Thermo Electron Corporation, San Jose, CA, USA). Prior to the analysis, protein spots from gels were cut out and subjected to a standard "in-gel digestion" procedure during which proteins were reduced with DTT, alkylated with iodoacetamide, and digested overnight with trypsin (sequencing Grade Modified Trypsin, Promega, Madison, USA). The peptide mixture was applied to a $R P-18$ precolumn (nanoACQUITY Symmetry ${ }^{\circledR}$ C18, Waters, Milford, USA) using water containing $0.1 \%(? / \mathrm{v})$ formic acid (FA) as a mobile phase and then transferred to a nano-HPLC RP-18 column (nanoACQUITY BEH C18, Waters $)$ using an acetonitrile gradient $(0-60 \%, \mathrm{v} / \mathrm{v}$, in $120 \mathrm{~min})$ in the presence of $0.05 \%(\mathrm{~m} / \mathrm{v})$ formic acid with a flow rate of $0.25 \mathrm{~mm}^{3} \mathrm{~min}^{-1}$. The column outlet was directly coupled with the ion source of the spectrometer working in the regime of data dependent MS to MS/MS switch (Florea et al. 2010).

After pre-processing the raw data with the Mascot Distiller v. 2.3 software (Matrix Science, London, UK), obtained peak lists were used to search the non-redundant protein database of the National Centre for Biotechnology Information (NCBI) (23919380 sequences; 8216485116 residues) of green plants clade using the Mascot search engine (v. 2.4, Matrix Science). Only peptides passing a Mascot-defined expectation value of 0.05 were considered as positive identifications (Krzywinska et al. 2016). The functional networks of differentially expressed proteins were constructed using the STRING database (Szklarczyk et al. 2017).

Statistical analysis: Statistical calculations were performed with the Statistica ${ }^{\circledR} 12$ package. The Duncan and Student $t$-tests based on one way ANOVA were used for detailed comparison of fluorescence parameters. For presentation of compressed fluorescence data, a heat map was created using the Heatmapper (www.heatmapper.ca). 


\section{Results}

In order to document differences in tolerance to drought, the rate of leaf dehydration was determined. The WSD was measured every $24 \mathrm{~h}$ for 4 consecutive days. Leaves of Ethos were drying out slower than leaves of Zebra. The WSD difference between cultivars was about $7 \%$ on the second day but about $20 \%$ on the third and fourth day (Table 1). Also, a difference was noticed in seedlings vitality. Plantlets dried to a $50 \%$ WSD recovered with different dynamics: 3days after re-watering ca. $70 \%$ of Ethos seedlings in comparison to ca. $30 \%$ of Zebra seedlings regained the initial pressure potential (data not shown).

Table 1. The water saturation deficit (WSD) in leaves of spring wheat cvs. Ethos (drought tolerant) and Zebra (drought sensitive) measured every $24 \mathrm{~h}$ for 4 consecutive days after disrupting watering.

\begin{tabular}{|c|c|c|c|c|c|}
\hline \multirow{2}{*}{ Cultivar } & \multicolumn{5}{|c|}{ WSD [\%] } \\
\hline & $0 \mathrm{~h}$ & $24 \mathrm{~h}$ & $48 \mathrm{~h}$ & $72 \mathrm{~h}$ & $96 \mathrm{~h}$ \\
\hline Ethos & $5 \mathrm{a}$ & $10 a b$ & $18 \mathrm{~b}$ & $46 \mathrm{~b}$ & $63 \mathrm{~b}$ \\
\hline Zebra & $4 \mathrm{a}$ & $15 \mathrm{a}$ & $25 \mathrm{a}$ & $64 \mathrm{a}$ & $84 \mathrm{a}$ \\
\hline
\end{tabular}

The consequences of tissue dehydration were reflected in changes of fluorescence parameters. Average linkage clustering using fluorescence parameters with Euclidean measurement of distances grouped studied samples in two main clusters (Fig. 1). Control seedlings and those having $15 \%$ WSD (both cultivars) as well as Ethos with $30 \%$ WSD were in close relative distances based on Chl a parameters. Ethos with $50 \%$ WSD as well as Zebra with 30 and $50 \%$ WSD were classified in the second cluster. The first cluster was characterized by relatively high values of $\mathrm{Chl} a$ fluorescence parameters (the green color on the heat map - Fig. 1) revealing the physiological similarities between cultivars under optimal conditions, with the exception of parameters RC/ABS (the amount of active reaction centers per absorption), 1$\mathrm{V}_{\mathrm{J}} / \mathrm{V}_{\mathrm{J}}$ (a measure of forward electron transport), and $\mathrm{PI}_{\mathrm{ABS}}$ (the performance index), for which relative values in Ethos leaves were close to zero (the dark colors on the heatmap). The only parameter, $\mathrm{T}_{\mathrm{fm}}$, was characterized by a red color meaning negative values for control seedlings. Seedlings from the second cluster were characterized by negative values of $\mathrm{Chl} a$ fluorescence parameters beside $\mathrm{T}_{\mathrm{fm}}$. In details, the declining trends of all measured

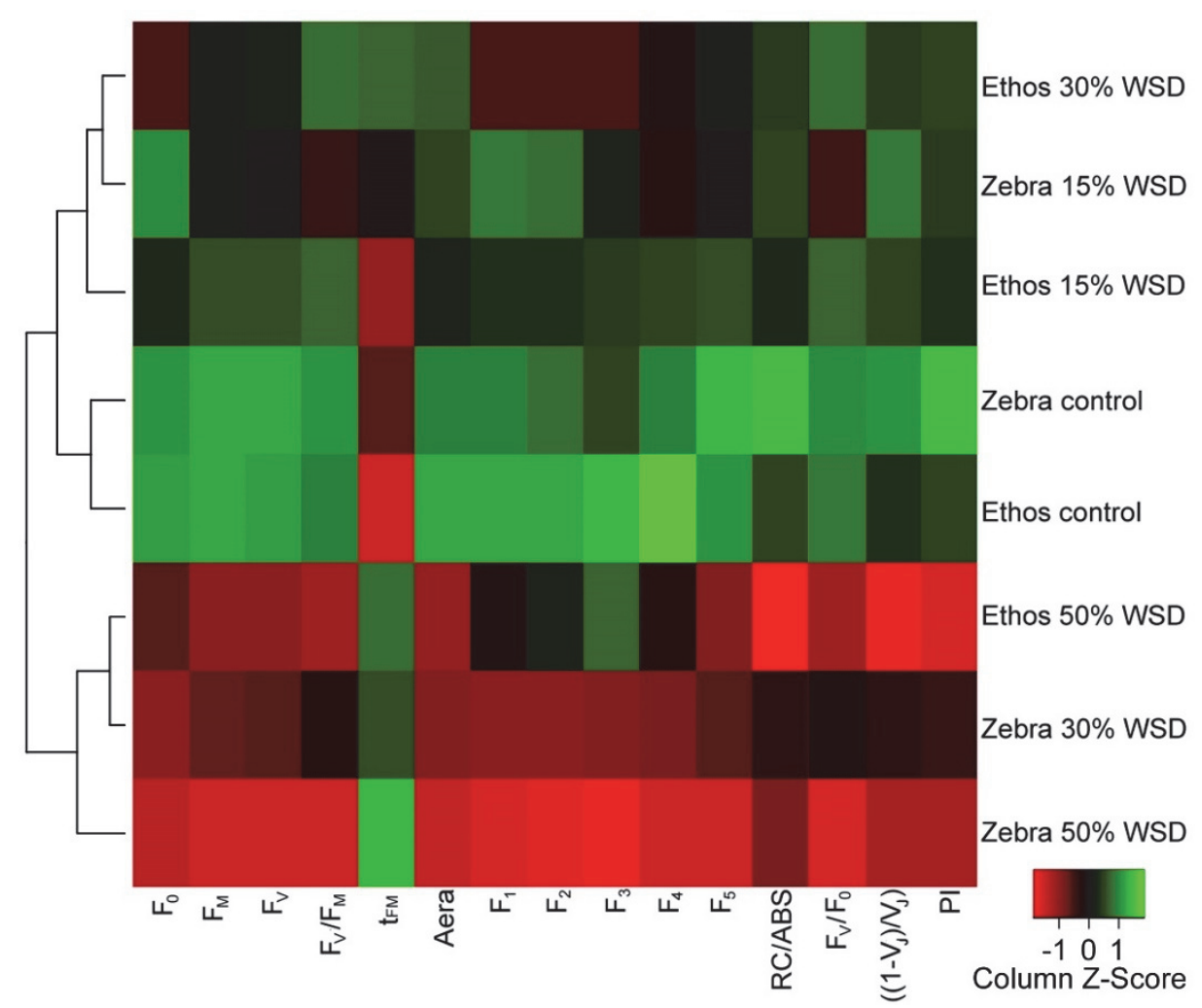

Fig. 1. The heat map of $\mathrm{Chl} a$ fluorescence parameters of cultivars differing in drought tolerance (Ethos - drought tolerant and Zebradrought sensitive) subjected to a progressive drought, which induced 15, 30, and 50\% water saturation deficit (WSD). The heat map was based on average linkage clustering with the Euclidean measurement of distances. 
parameters, except $T_{\text {fm }}$, were detected with increasing tissue dehydration (Table 1 Suppl.). For Ethos, most significant differences were found between the control and seedlings with $15 \%$ WSD; further, the drought did not cause changes in fluorescence parameters. For Zebra, the parameters decreased consistently, and statistically significant differences $(P \leq 0.05)$ were detected between seedlings with 30 and $50 \%$ WSD. The average fluorescence transients (Fig. 2) showed that plants subjected to the drought were characterized by lower values of curves than control plants. The points of inflection $\mathrm{J}$ at $2.0 \mathrm{~ms}$ and $\mathrm{I}$ at $30 \mathrm{~ms}$ are important for result interpretations. Other points of inflections, $\mathrm{L}$ at 150 $\mu \mathrm{s}$ and $\mathrm{K}$ at $300 \mu \mathrm{s}$, identified and described by Strasser et al. (1995), were so small that their visualization as local extremes were possible after subsequent mathematical processing by differentiating twice normalized fluorescence transients for plants subjected to the drought and for control ones. On $\Delta \mathrm{W}_{\mathrm{OJ}}$ curves, the $\mathrm{K}$ point of inflection appeared at about $0.3 \mathrm{~ms}$. For Ethos, the normalized curve for seedlings with $15 \%$ WSD had a negative sign and for leaves dehydrated to $30 \%$ was nearly zero, whereas seedlings dehydrated to $50 \%$ WSD had a maximum value of +0.05 (Fig. 2). In the case of Zebra, all dehydration states resulted in positive signs of $\Delta \mathrm{W}_{\mathrm{OJ}}$ curves.

Differences between profiles on the images of the Commassie-stained 2D gels were found using the Delta2 software. This software enables a positional correction of gel images by combination of global and local image transformations followed by image fusion to the proteome map (Berth et al. 2007). The principal component analysis, based on correlation matrix algorithm for vector data of protein spot positions, revealed gel grouping in accordance with seedling WSDs and indicated similar proteomic profiles by similar locations in the coordinate system. In the case of Ethos, most different were gels obtained from control plants and from seedlings dehydrated to $50 \%$ WSD. All stages of Ethos dehydration caused clear gel image grouping. In contrast, the proteomes of Zebra control seedlings and those dehydrated to $30 \%$ WSD were grouped diagonally with nearly no differences between control and $15 \%$ WSD (Fig. 1 Suppl.).

Totally, 850 spots were reproducibly detected in a $\mathrm{pH}$ range of $4-7$ and a molecular mass range of 14.4 $120 \mathrm{kDa}$ with 80 differential drought-responsive ones (Fig. 2 Suppl.). Among 40 differential proteins of Ethos, only 3 proteins were downregulated: one at each dehydration state. The number of drought induced proteins in Ethos leaves were 1/3 higher at the beginning of the drought treatment than at the end (Fig. 3, Table 2 Suppl.). At the same time, out of 40 differential proteins of Zebra, about 2/3 were downregulated. All differentially induced proteins at $15 \%$ WSD were downregulated. In Zebra leaves with $50 \%$ WSD, 10 upregulated proteins were detected (Fig. 3, Table 3
Suppl.). So, the cultivars differed in dynamics of proteomic response to dehydration. The LC/MS analysis followed by Mascot protein identification revealed cultivar dependent functional differences among those proteins (Tables 2 and 3 Suppl.).

In Ethos, 19 differential proteins related to photosynthesis/energy metabolism were identified. The only 3 proteins of all different proteins were downregulated: a chloroplast light-harvesting chlorophyll $a / b$ binding protein (at $15 \%$ WSD) and 2 proteins identified as a Rubisco small subunit (at 30 and $50 \%$ WSD). The other identified proteins were: ribulose bisphosphate carboxylase/oxygenase activase and carbonic anhydrase induced in response to $15 \%$ WSD; glycine dehydrogenase (30\% WSD), and chloroplast glyceraldehyde-3-phosphate dehydrogenase (50\% WSD). Seven differential protein spots were identified as transketolase either by direct matching by Mascot or by blasting Mascot predicted proteins to the NCBI database. Two NCBI hits: gi| 326533372 and gi| 357110873 were detected as 3 spots induced in response to 15 or $30 \%$ WSD, respectively. Three proteins were identified as ribose-5-phosphate isomerase (15\% WSD). Peptides which matched the same NCBI number were considered as isoenzymes. The other enzymes were identified as: chloroplast fructose-bisphosphate aldolase and mitochondrial succinyl-CoA ligase [ADP-forming] subunit beta (50\% WSD). Similarly, 40 differential spots in Zebra were identified as photosynthesis/energy metabolism related. Only 3 proteins were upregulated: chlorophyll $a / b$ binding protein in response to $50 \%$ WSD and ATP synthase delta subunit in response to 30 and $50 \%$ WSD. Other proteins were downregulated: 7 spots matched 3 different NCBI accessions of ribulose bisphosphate carboxylase in response to all stages of dehydration, 3 spots matched one NCBI accession of carbonic anhydrase in response to 30 and $50 \% \mathrm{WSD}$, 3 spots influenced by $50 \%$ WSD matched 2 accessions of transketolase, and 1 glyoxysomal malate dehydrogenase. Phosphoglycerate mutase was found as downregulated in response to 15 and $30 \% \mathrm{WSD}$. The $\mathrm{NAD}(\mathrm{P}) \mathrm{H}$-quinone oxidoreductase subunit $\mathrm{S}$ was also downregulated in leaves dehydrated to $15 \%$ WSD.

In the Ethos proteome, all 6 protein spots related to metabolism were upregulated and 3 of them matched glutamine synthetase isoform GS2c and its precursor (at 15 and $50 \%$ WSD). Also, 50S ribosomal protein L21 was upregulated in response to $15 \%$ WSD, whereas metacspase 1 and rubber elongation factor in response to $30 \%$ WSD. In the Zebra proteome, among 7 spots related to metabolism, glutamine synthetase was upregulated in response to $50 \% \mathrm{WSD}$. In response to $15 \% \mathrm{WSD}$, ribosomal 50S protein, alkaline phosphatase, and elongation factor 1-alpha were downregulated. Glutamate-1-semialdehyde 2,1-aminomutase was downregulated in response to 30 and $50 \%$ WSD, whereas single-stranded nucleic acid binding protein in response 


\section{NYKIEL et al.}

\section{to $50 \% \mathrm{WSD}$.}

In the proteome of Ethos, 9 stress-related proteins were upregulated: 4 chloroplastic-like peptidyl-prolyl cistrans isomerases CYP38 were induced at all levels of the dehydration and matched 2 accessions. Protein degradation 26S proteasome and chaperone protein ClpC1-chloroplastic-like were induced at $15 \% \mathrm{WSD}$, whereas the precursor of protein disulfide isomerase was upregulated at $30 \%$ WSD. Two heat-shock proteins (HSP70) were induced at 15 and $30 \%$ WSD. Zebra responded to $50 \%$ WSD by upregulation of 2 protein spots: LEA/Cor protein and phosphoethanolamine methyltransferase. The $30 \%$ WSD resulted in downregulation of 2 proteins matching thioredoxine, whereas

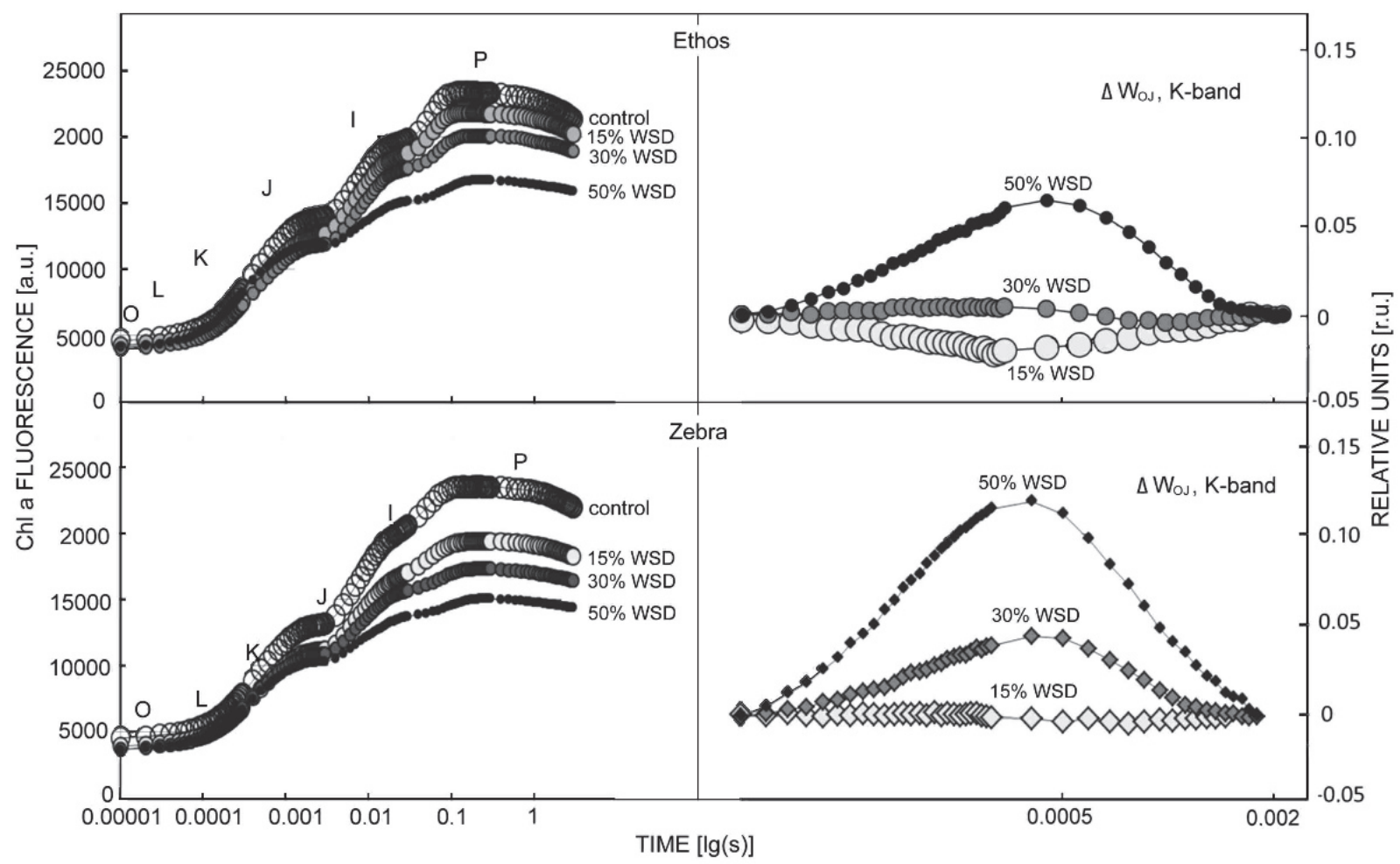

Fig. 2. Chlorophyll $a$ fluorescence transients (OJIP curves) in dark adapted leaves of wheat seedlings cvs. Ethos and Zebra subjected to a gradual drought stress as compared with those grown under control conditions. Plots are given on a logarithmic time scale. On the left - the fluorescence curves with marked time points: fluorescence intensity at: $\mathrm{O}-0.05 \mathrm{~ms}, \mathrm{~L}-0.15 \mathrm{~ms}, \mathrm{~K}-0.30 \mathrm{~ms}, \mathrm{~J}-2 \mathrm{~ms}$, I - $30 \mathrm{~ms}$, and $\mathrm{P} 1 \mathrm{~s}$, which is the maximum fluorescence denoted as $\mathrm{t}_{\mathrm{FM}}$. On the right $-\Delta \mathrm{W}_{\mathrm{OJ}}$ is the difference of double normalized data at points $F_{O}$ and $F_{J}$ for each cultivar subjected to drought vs. control conditions, where $W_{O J}=\left[\left(F_{t}-F_{O}\right) /\left(F_{J}-F_{O}\right)\right]$, and shows disturbances at $\mathrm{K}$ point.

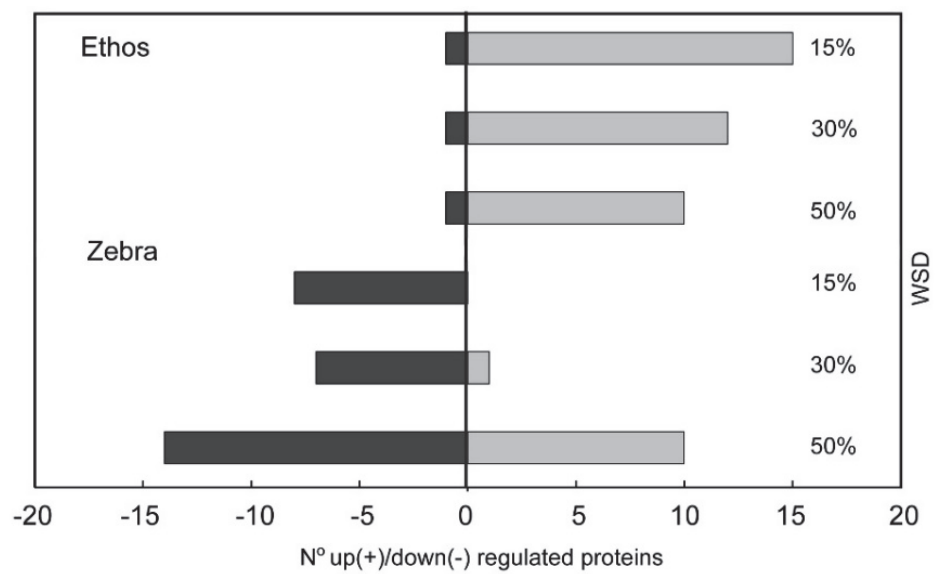

Fig. 3. The influence of drought stress on number of up- and down-regulated proteins detected using the Delta 2 software in wheat cvs. Ethos and Zebra. Proteins were extracted from leaves subjected to dehydration inducing 15, 30, and $50 \%$ water saturation deficit (WSD) and compared with a control. 
$50 \%$ WSD induced downregulation of chaperone protein ClpC1. Protein spot matching rhodanese homology domain, the alpha beta fold domain, found as participating in signaling an classified as a defense protein, was suppressed in response to 15 and $50 \%$ WSD.

Only $50 \%$ WSD induced upregulation of ROS detoxifying enzymes in the Ethos proteome: 2 ascorbate peroxidases matching the same accession, dehydroascorbate reductase, and peroxidase like protein.
Similarly, in Zebra proteome, upregulation of ROS detoxifying enzymes (thylakoid bound ascorbate peroxidase, ascorbate peroxidase, peroxidase like, and ferritin), and downregulation of dehydrogenese/reductase short chain were detected in response to $50 \%$ WSD. Cytoskeleton was affected in Ethos by actin protein upregulations in response to 15 and $30 \%$ WSD. The graphical presentation of computationally generated functional networks of proteins using the STRING database are presented in Fig. 4.

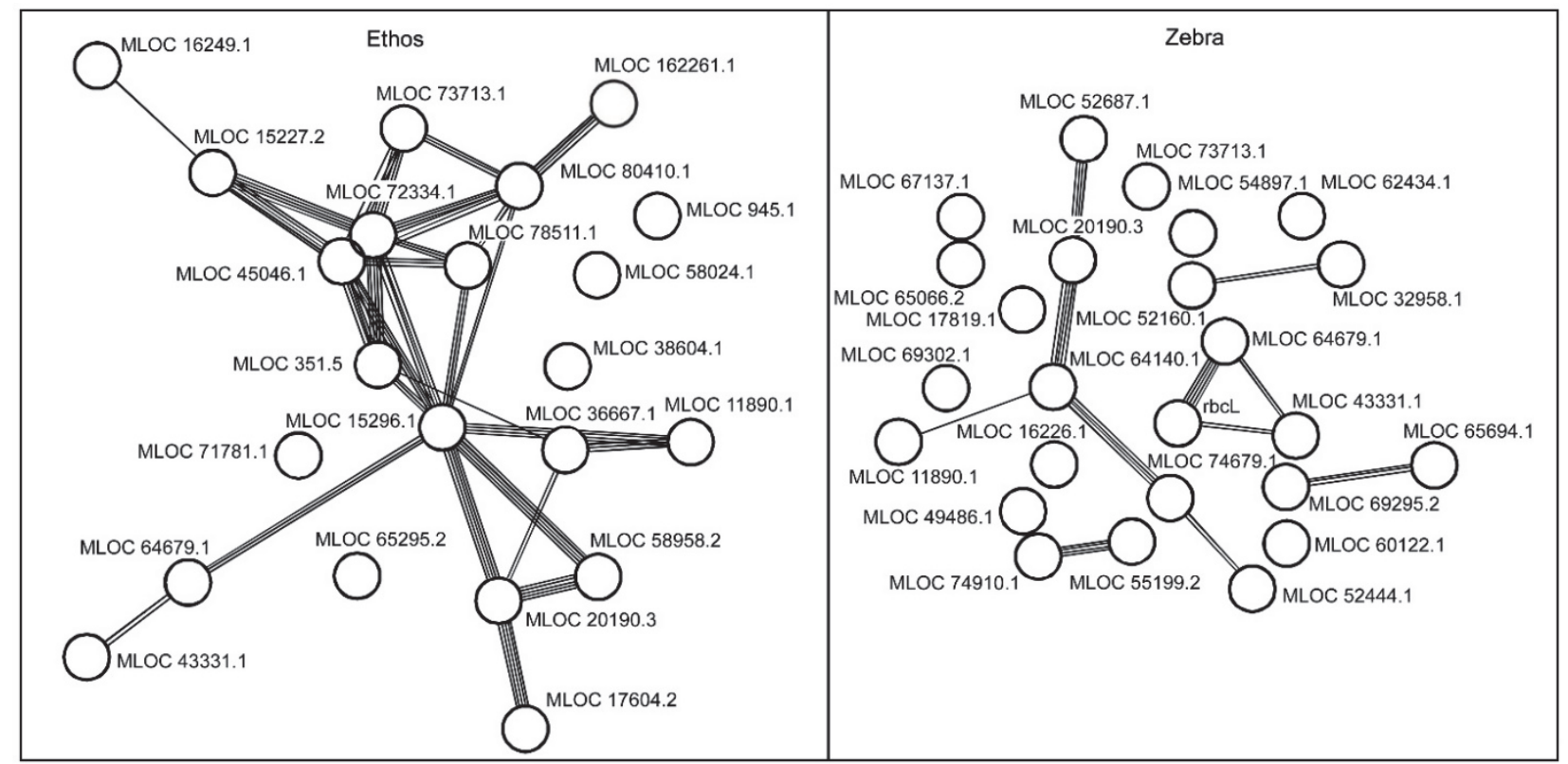

Fig. 4. Computational prediction of the functional network of proteins in cvs. Ethos and Zebra using the STRING software. The proteins used for analysis are presented in Tables 2 and 3 Suppl. The color graphics was changed to white and black one. All nodes were drawn in white, the number of connecting lines is in proportion to size of information about protein interactions.

\section{Discussion}

The 11-d-old spring wheat seedlings were used for studies because at this developmental stage, drought tolerance, characteristic for germination, is lost (Miazek et al. 2017). Additionally, that stage can be critical for yield in field conditions due to possible inhibition of tillering. Detected differences in WSD as well as in seedling vitality confirmed by Chl $a$ fluorescence data pointed out that Ethos is a drought tolerant cultivar in terms of the Levitt (1980) definition (Table 1, Fig. 2, Table 1 Suppl.). However, it should be kept in mind that drought tolerance is always a temporary phenomenon strongly depending on the stress intensity and duration. Often, the physiological response to stress is only shifted in time (Miazek et al. 2017), which was well illustrated by the fluorescence parameters. Quick visual comparison by clustering fluorescence parameters divided samples in accordance to drought tolerance and dehydration rate (Fig. 1). Clustering data at $30 \% \mathrm{WSD}$ to different groups suggested, that state of PS II in Ethos at $30 \%$ WSD was similar to that of controls grown in optimal conditions, whereas PS II in Zebra leaves was similar to that in most dehydrated plants (Fig. 1). To our knowledge, cluster analysis and heat maps were not used for comparison of Chl $a$ fluorescence data till now. We think that it is a good way of data visualization for comparison of the studied species and if assisted with double normalized fluorescence data as $\Delta \mathrm{W}_{\mathrm{OJ}}$, curves allows a quick comparison and selection of tested materials (Figs. 1 and 2) (Prokopiuk et al. 2018). The data of fluorescence transient (up to $1 \mathrm{~s}$ ) reflect the dynamics of flow of light induced electrons through ETC of PS II. Disturbances in electron flow along ETC induced by plants dehydration and sink dependent slowdown are visible directly as local inflection points on $\Delta \mathrm{W}_{\mathrm{OJ}}$ curves, appearing as maxima for drought susceptible plants (Oukarroum et al. 2007). With such assessments, Ethos performed as a drought tolerant at 15 and $30 \% \mathrm{WSD}$ (the minimum on $\Delta \mathrm{W}_{\mathrm{OJ}}$ curves), whereas Zebra was drought sensitive from the 
beginning of the experiment (Oukarroum et al. 2007). The authors of this article believe, that more studies on OJIP application may lead to a simplification of the methods used in automatic phenotyping because of the fact that the experimental procedure of OJIP transient registration is direct, immediate, non-laborious, and can be automated (Paunov et al. 2018).

In addition, a faster decrease of measured parameters in Zebra leaves in response to dehydration pointed on its a lower tolerance to drought. Changes were consistent with literature data (Oukarroum et al. 2007, Paunov et al. 2018). The initial fluorescence $\left(\mathrm{F}_{0}\right)$ (an indicator of the oxidation state of quinone $\mathrm{Q}_{\mathrm{A}}$ ) did not differentiate studied cultivars at any dehydration state, but other measured values $\left(\mathrm{F}_{1}-\mathrm{F}_{5}\right)$ did, with a statistical importance, mainly at 15 and $30 \%$ WSD (Table 1 Suppl.). The decreasing value of $\mathrm{F}_{\mathrm{M}}$, related to a decreasing rate of $\mathrm{Q}_{\mathrm{A}}$ reduction in parallel with the positive signs of double normalized curves $\Delta \mathrm{W}_{\mathrm{OJ}}$ pointed on earlier (at 15 and $30 \% \mathrm{WSD}$ ) reaction to dehydration in Zebra leaves (Fig. 2) (Oukarroum et al. 2007, Paunov et al. 2018). The calculated parameters also changed in accordance to the stress duration as well as plants tolerance. In leaves of Ethos, differences between 30 and $50 \%$ WSD were noted, whereas in Zebra from the beginning of stress duration, the parameters differed in accordance to cultivar drought sensitivity (Stirbet et al. 2018). The performance index of PS II has been confirmed as a sensitive indicator of water stress (Zivcak et al. 2008). It reflects an effective antenna size, the primary quantum yield of PS II, and differences in formation of local inflection points (JIP). The Area reflects a reduced plastoquinone pool and is related to the number of electrons that must be transported through ETC before fluorescence reaches its maximum value $\left(F_{M}\right)$. Lower values are characteristic for stress susceptible plants. The fact, that in leaves at $15 \% \mathrm{WSD}$, the time to reach $\mathrm{F}_{\mathrm{M}}\left(\mathrm{T}_{\mathrm{FM}}\right.$, related to the number of photons absorbed) was longer in Ethos leaves, pointed additionally on better drought tolerance of that cultivar (Stirbet et al. 2018). Presented parameters are more sensitive markers of drought tolerance than commonly used $\mathrm{F}_{\mathrm{V}} / \mathrm{F}_{\mathrm{M}}$ and $\mathrm{F}_{\mathrm{V}} / \mathrm{F}_{0}$, which describe the maximum quantum yield of PS II (Kalaji et al. 2018). Indeed, the parameter $\mathrm{F}_{\mathrm{V}} / \mathrm{F}_{\mathrm{M}}$, did not differentiate Ethos from Zebra, whereas $\mathrm{F}_{\mathrm{V}} / \mathrm{F}_{0}$ pointed on better Ethos performance at $15 \%$ WSD. The $\mathrm{F}_{\mathrm{V}} / \mathrm{F}_{\mathrm{M}}$ and $\mathrm{F}_{\mathrm{V}} / \mathrm{F}_{0}$ were found as informative markers of tolerance to cold (Rapacz et al. 2015) or to heavy metals (Żurek et al. 2014, Paunov et al. 2018), but not to drought (Burke 2007, Rollins et al. 2013). However, additional treatment of dehydrated leaves by elevated temperatures enabled the reference of $\mathrm{F}_{\mathrm{V}} / \mathrm{F}_{\mathrm{M}}$ to the drought tolerance (Burke 2007, Rollins et al. 2013).

The disturbances in photosynthesis influence carbon assimilation and finally all life processes and are reflected in proteome modifications. Parallel analysis of fluorescence and proteomic data can enrich our understanding about mechanisms of drought stress tolerance (Cabrera-Bosquet et al. 2012).

Detected differences in patterns of Rubisco degradation are consistent with literature data showing that a decreasing activity of Rubisco can be an indicator of plant response to the stress (Oliver et al. 2011, Pinheiro and Chaves 2011). In drought sensitive wheat cultivars as well as in those which were not tolerant to drought due to lack of acclimatization an immediate decrease of Rubisco was detected (Nagy et al. 2013). Degradation of Rubisco subunits is considered as a process associated with the suppression of photosynthesis (Pinheiro and Chaves 2011) noticed on $\Delta \mathrm{W}_{\mathrm{OJ}}$ curves in leaves of Zebra from the beginning of drought and in Ethos only in response to $50 \%$ WSD (Fig. 2, Tables 2 and 3 Suppl.).

Due to regulation of Rubisco activase, differences in drought tolerance could be assumed (Portis 1995). In our experiment, the intensity of the spot identified as Rubisco activase increased in Ethos leaves in response to $15 \%$ WSD with a simultaneous absence of Rubisco subunit degradation. However, in Zebra, Rubisco activase downregulation was detected in all dehydration stages. Upregulation of carbonic anhydrase and downregulation of chloroplast $a / b$ light harvesting complex were detected as early responses to drought in leaves of Ethos. Carbonic anhydrase improves $\mathrm{CO}_{2}$ supply to Rubisco, when stomata are becoming closed upon the stress (Igamberdiev 2015), so upregulation of this enzyme could positively influence photosynthesis. Parallel reduction of spots of light harvesting complexes of PS II could be interpreted as a decrease of the energy capture and so protection against excessive energy absorption and danger of ROS formation_(Demidchik 2015). In leaves of Zebra, downregulation of carbonic anhydrase might decline $\mathrm{CO}_{2}$ supply to Rubisco slowing down photosynthesis. Parallel upregulation of the light harvesting complex of PS I may suggest that the cyclic reactions of photosynthesis generate energy in form of ATP but not as NADPH to stabilize the redox homeostasis (Yadav et al. 2017).

In leaves of Zebra, downregulation of lyoxysomal malate dehydrogenase, one of the key enzyme of citric acid cycle, was detected and regarded as a sign of downregulation of metabolism in response to drought (Musrati et al. 1998). Glycine dehydrogenase, malate dehydrogenase, and carbonic anhydrase were upregulated in leaves of Ethos and downregulated in Zebra. That proteomic data went along with OJIP evidence of a higher photosynthetic activity in Ethos seedlings (Fig. 2, Tables 2 and 3 Suppl.). On the other hand, conclusions about downregulation of Zebra metabolism have been strengthened by a detected worse regeneration of Zebra seedlings after re-watering (data not shown).

Additionally, detected upregulation of mitochondrial glycine dehydrogenase, the main enzyme of 
photorespiration, in Ethos leaves at $30 \%$ WSD should improve plant performance at water scarcity (Voss et al. 2013, Bykova et al. 2014). Our experiments showed upregulation of glyceraldehyde-3-phosphate dehydrogenase, the enzyme of glycolysis, in severely dehydrated Ehtos leaves. Xu et al. (2013) suggested that maintenance of active glyceraldehyde-3-phosphate dehydro-genase could be an important factor in drought tolerance of Kentucky bluegrass cultivars.

Our findings proved that energy and metabolism related proteins were upregulated in Ethos, whereas in Zebra most of them were downregulated. It suggests that the photosynthetic activity was protected in Ethos leaves at least in response to 15 and $30 \%$ WSD. Particular attention should be paid to transketolase, which was the most abundant differentially expressed protein in Ethos seedlings. That enzyme participates in several pathways by linking pentose phosphate pathway with glycolysis and with tricarboxylic acid cycle. It is involved in synthesis of ribulose-5-phosphate as well as in erythrose4-phosphate, the precursor of shikimate pathway. Synthesis of ribulose-5-phosphate is also a regeneration part of the Calvin cycle. Thus, upregulation of transketolase in leaves of a drought tolerant cultivar in contrast to a sensitive one could positively influence cell metabolism in several ways and improve plant performance in stress conditions (Kochetov and Solovjeva 2014). The other enzymes participating in regeneration of Calvin cycle and upregulated in Ethos were: ribose-5-phosphate isomerase (detected in leaves subjected to $15 \%$ WSD) and chloroplast fructose biphosphate aldolase (detected under $50 \%$ WSD). Upregulation of aldolase in the proteome of a drought tolerant cultivar along with actin and HSP70 proteins strengthens the supposition about the involvement of those proteins in redox signal transduction through the cytosol by the redox-dependent compartmentation of glycolytic enzymes in mitochondria and actin cytoskeleton (Wojtera-Kwiczor et al. 2012). Upregulation of mitochondrial succinyl CoA ligase forming ADP in citric acid cycle in response to drought in Ethos leaves completed the evidence about upregulation of metabolism in drought tolerant cultivars (Araujo et al. 2011). On the other hand, downregulation of phosphoglycerate mutase in the Zebra proteome, an important enzyme of glycolysis which catalyze the transfer of the phosphate group between the $3^{\text {rd }}$ and $2^{\text {nd }}$ carbon of phosphoglycerate, suggested slowing down of Zebra metabolism in response to dehydration (Zhao and Assmann 2011).

Disruption of photosynthesis impacted the

\section{References}

Araujo, W.L., Nunes-Nesi, A., Nikoloski, Z., Sweetlove, L.J., Fernie, A.R.: Metabolic control and regulation of the tricarboxylic acid cycle in photosynthetic and heterotrophic disturbances between energy generation and carbon metabolism. In Zebra leaves, upregulation of glutamine synthetase, which is the central enzyme of nitrogen assimilation and downregulation of most of other proteins at the same time, may point to the accelerated nitrogen assimilation as a way of tissues protection against ROS and excessive ATP formation (Gietler et al. 2016, Habash et al. 2014). An upregulation of 50S ribosomal protein, engaged in protein turnover, in Ethos confirmed cultivardependent differences in response to drought (Olinares et al. 2011, Sadanandom et al. 2012, Scheibe et al. 2013). Additionally, in Zebra DNA protection seemed to be impaired upon drought due to downregulation of singlestranded nucleic acid binding protein as well as the inhibition of metabolism due to downregulation of glutamate-1-semialdehyde amino-mutase and a nonspecific alkaline phosphatase (Nishiyama et al. 2011, Geigenberger and Fernie 2014).

Upregulation of peptidyl propyl cis-trans isomerase (CYP38) in Ethos leaves at $50 \%$ WSD ensured the maintenance of PS II activity (Wang et al. 2015), whereas upregulation of chaperone protein HSP70 should prevent proteins against aggregation (Park and Seo 2015). Upregulation of $26 \mathrm{~S}$ along with chloroplast chaperoneperoxidase $\mathrm{ClpC1}$ and 50S ribosomal protein as well as disulfide isomerase (regulating protein translation in redox-dependent manner) pointed on the intense protein turnover in Ethos, whereas downregulation of $\mathrm{ClpC} 1$ as well as 50S ribosomal protein in Zebra might indicate slowdown of protein turn-over (Olinares et al. 2011, Sadanandom et al. 2012, Scheibe et al. 2013). The LEA/Cor protein with a protective function in dehydrated tissues was upregulated in Zebra. Also, upregulation of phosphoethanolamine methyl-transferase, an enzyme participating in reconstruction of cell membranes, was detected in drought sensitive cultivar (Charron et al. 2002). It seems that the ability to survive drought is built in Zebra leaves by an increase in membrane protection.

In conclusion: 1) Curves of Chl a fluorescence transient OJIP varied between the drought tolerant and the drought susceptible cultivar. 2) Proteome rebuilding and photosynthesis protection were detected as a mechanism induced in seedlings of drought tolerant cultivar. 3) Comparison of proteome alterations in cultivars differing in drought tolerance allowed identification of protein assured drought tolerance. 4) Computational prediction of the functional networks of identified differential proteins for each cultivar, using the STRING software, showed strong interactions within each group.

plant tissues. - Plant Cell Environ. 35: 1-21, 2011.

Berth, M., Moser, F.M., Kolbe, M., Bernhardt, J.: The state of the art in the analysis of two-dimensional gel electropho- 
resis images. - Appl. Microbiol. Biotechnol. 76: 1223-1243, 2007.

Blum, A.: Drought resistance - is it really a complex trait? Funct. Plant Biol. 38: 753-757, 2011.

Burke, J.J.: Evaluation of source leaf responses to water-deficit stresses in cotton using a novel stress bioassay. - Plant Physiol. 143: 108-121, 2007.

Bykova, N.V., Moller, I.M., Gardeström, P., Igamberdiev, A.U.: The function of glycine decarboxylase complex is optimized to maintain high photorespiratory flux via buffering of its reaction products. - Mitochondrion 19: 357-364, 2014.

Cabrera-Bosquet, L., Crossa, J., Von Zitzewitz, J., Serret, M.D., Araus, L.J.: High-throughput phenotyping and genomic selection. - J. Integr. Plant Biol. 54: 312-320, 2012.

Charron, J.-B.F., Breton, G., Danyluk, J., Muzac, I., Ibrahim, R.K., Sarhan, F.: Molecular and biochemical characterization of a cold-regulated phosphoethanolamine N-methyltransferase from wheat. - Plant Physiol. 129: 363373, 2002.

Curtis, B.: Wheat in the world. - In: Curtis B., Rajaram S., Gómez-Macpherson H. (ed.): Bread Wheat - Improvement and Production. Pp. 1-16, FAO, Rome 2002.

Demidchik, V.: Mechanisms of oxidative stress in plants: from classical chemistry to cell biology -. Environ. exp. Bot. 109: 212-228, 2015.

Florea, B.I., Verdoes, M., Li, N., Van der Linden, W.A., Geurink, P.P., Van den Elst, H., Hofmann, T., De Ru, A., Van Veelen, P.A., Tanaka, K., Sasaki, K., Murata, S., Den Dulk, H., Brouwer, J., Ossendorp, F.A., Kisselev, A.F., Overkleeft, H.S.: Activity-based profiling reveals reactivity of the murine thymoproteasome-specific subunit $\beta 5 \mathrm{t}$. Chem. Biol. 17: 795-801, 2010.

Foyer, C.H., Noctor, G.: Redox sensing and signalling associated with reactive oxygen in chloroplasts, peroxisomes and mitochondria. - Physiol. Plant. 119: 355364, 2003.

Foyer, C.H., Noctor, G.: Ascorbate and glutathione: the heart of the redox hub. - Plant Physiol. 155: 2-18, 2011.

Geigenberger, P., Fernie, A.R.: Metabolic control of redox and redox control of metabolism in plants. - Antiox. Redox Signal. 21: 1389-1421, 2014.

Gietler M., Nykiel M., Orzechowski S., Fettke J., Zagdańska B.: Proteomic analysis of S-nitrosylated and S-glutathionylated proteins in wheat seedlings with different dehydration tolerances. - Plant Physiol. Biochem. 108: 507-518, 2016.

Goltsev V.N., Kalaji H.M., Paunov M., Bąba W., Horaczek T., Mojski J., Kociel H., Allakhverdiev S.I.: Variable chlorophyll fluorescence and its use for assessing physiological condition of plant photosynthetic apparatus. Russ. J. Plant Physiol. 63: 869-893, 2016.

Grudkowska, M., Zagdanska, B. Acclimation to frost alters proteolytic response of wheat seedlings to drought. - J. Plant Physiol. 167: 1321-1327, 2010.

Grudkowska, M., Zagdańska, B., Rybka, Z.: [Tolerance of spring wheat to soil drought at a heading phase.] - Biul. IHAR 228: 51-60, 2003. [In Polish, ab: E.]

Habash, D.Z., Baudo, M., Hindle, M., Powers, S.J., DefoinPlatel, M., Mitchell, R., Saqi, M., Rawlings, C., Latiri, K., Araus, J.L., Abdulkader, A., Tuberosa, R., Lawlor, D.W., Nachit, M.M.: Systems responses to progressive water stress in durum wheat. - PLoS ONE 9: e108431, 2014.

Igamberdiev, A.U.: Control of rubisco function via homeostatic equilibration of $\mathrm{CO}_{2}$ supply. - Front. Plant Sci. 6: 106, 2015.
Jogaiah S., Govind S.R., Tran L.S.P.: Systems biology-based approaches toward understanding drought tolerance in food crops. - Crit. Rev. Biotechnol. 33: 23-39, 2013.

Kalaji, H.M., Rastogi, A., Živčák, M., Brestic, M., Daszkowska-Golec, A., Sitko, K., Alsharafa, K.Y., Lotfi, R., Stypiński, P., Samborska, I.A., Cetner, M.D. Prompt chlorophyll fluorescence as a tool for crop phenotyping: an example of barley landraces exposed to various abiotic stress factors. - Photosynthetica 56: 953-961, 2018.

Kochetov, G.A., Solovjeva, O.N.: Structure and functioning mechanism of transketolase. - Biochim. Biophys. Acta 1844: 1608-1618, 2014.

Kopczewski, T., Kuźniak, E.: Redox signals as a language of interorganellar communication in plant cells. - Centr. Eur. J. Biol. 8: 1153-1163, 2013.

Krzywińska E., Bucholc M., Kulik A., Ciesielski A., Lichocka M., Dębski J., Ludwików A., Dadlez M., Rodriguez P.L., Dobrowolska G. Phosphatase ABI1 and okadaic acidsensitive phosphoprotein phosphatases inhibit salt stressactivated SnRK2.4 kinase. BMC Plant Biology 16: 136, 2016.

Levitt, J.(ed.): Responses of Plants to Environmental Stresses. Vol. II. Water, Radiation, Salt and Other Stresses. $2^{\text {nd }}$ Ed. Academic Press, New York - San Francisco - London 1980.

Marín, D., Martín, M., Serrot, P.H., Sabater, B.: Thermodynamic balance of photosynthesis and transpiration at increasing $\mathrm{CO}_{2}$ concentrations and rapid light fluctuations. Biosystems 116: 21-26, 2014.

Miazek, A., Nykiel, M., Rybka, K.: Drought tolerance variation depends on the age of the spring wheat seedlings and results in differentiated pattern of proteinases on zymography gels. - Russ. J. Plant Physiol. 64: 333-340, 2017.

Miller, G., Suzuki, N., Ciftci-Yilmaz, S., Mittler, R.: Reactive oxygen species homeostasis and signalling during drought and salinity stresses. - Plant Cell Environ. 33: 453-467, 2010.

Moller, I.M.: Plant mitochondria and oxidative stress: electron transport, NADPH turnover, and metabolism of reactive oxygen species. - Ann. Rev. Plant Physiol. Plant mol. Biol. 52: 561-591, 2001.

Musrati, R.A., Kollarova, M., Mernik, N., Mikulasova, D.: Malate dehydrogenase: distribution, function and properties. - Gen. Physiol. Biophys. 17: 193-210, 1998.

Nagy, Z., Nemeth, E., Guoth, A., Bona, L., Wodala, B., Pecsvaradi, A.: Metabolic indicators of drought stress tolerance in wheat: glutamine synthetase isoenzymes and Rubisco. - Plant Physiol. Biochem. 14: 48-54, 2013.

Nishiyama, Y., Allakhverdiev, S.I., Murata, N.: Protein synthesis is the primary target of reactive oxygen species in the photoinhibition of photosystem II. - Physiol. Plant. 142: 35-46, 2011.

Noctor, G., Mhamdi, A., Foyer, C.H.: The roles of reactive oxygen metabolism in drought: not so cut and dried. - Plant Physiol. 164: 1636-1648, 2014.

Olinares, P.D.B., Kim, J., Van Wijk, K.J.: The Clp protease system: a central component of the chloroplast protease network. - Biochim. biophys. Acta 1807: 999-1011, 2011.

Oliver, M.J., Jain, R., Balbuena, T.S., Agrawal, G., Gasulla, F., Thelen, J.J.: Proteome analysis of leaves of the desiccationtolerant grass, Sporobolus stapfianus, in response to dehydration. - Phytochemistry 72: 1273-84, 2011.

Oukarroum A., Madidi S.E., Schansker G., Strasser R.J.: Probing the responses of barley cultivars (Hordeum vulgare 
L.) by chlorophyll $a$ fluorescence OLKJIP under drought stress and re-watering. - Environ. exp. Bot. 60: 438-446, 2007.

Park, C.-J., Seo ,Y.-S.: Heat shock proteins: a review of the molecular chaperones for plant immunity. - Plant Pathol. J. 31: 323-333, 2015

Paunov, M., Koleva, L., Vassilev, A., Vangronsveld, J., Goltsev, V.: Effects of different metals on photosynthesis: cadmium and zinc affect chlorophyll fluorescence in durum wheat. - Int. J. mol. Sci. 1: 787, 2018.

Pinheiro, C., Chaves, M.M.: Photosynthesis and drought: can we make metabolic connections from available data? - J. exp. Bot. 62: 869-882, 2011.

Portis, A.R.: The regulation of Rubisco by Rubisco activase. - J. Exp. Bot. 46: 1285-1291, 1995.

Prokopiuk, K., Żurek, G., Rybka, K. Turf covering for sport season elongation cause no stress for grass species as detected by Chl $a$ fluorescence. - Urban Forestry and Urban Greening_2018 in press.

Rapacz, M., Sasal, M., Kalaji, H.M., Kościelniak, J.: Is the OJIP test a reliable indicator of winter hardiness and freezing tolerance of common wheat and triticale under variable environments? - PLoS ONE 10: e0134820, 2015.

Rollins, J.A., Habte, E., Templer, S.E., Colby, T., Schmidt, J., von Korff, M.: Leaf proteome alterations in the context of physiological and morphological responses to drought and heat stress in barley (Hordeum vulgare L.). - J. exp. Bot. 64: 3201-3212, 2013.

Rybka, K., Nita, Z.: [Modern phenotypes of cereals for growing in areas endangered with drought.] - Biul. IHAR 273: 5572, 2014. [In Polish, ab: E.]

Sadanandom, A., Bailey, M., Ewan, R., Lee, J., Nelis, S.: The ubiquitin-proteasome system: central modifier of plant signalling. - New Phytol. 196: 13-28, 2012.

Scheibe, R., Zachgo, S., Hanke, G.T.: Plant cell microcompartments: a redox-signaling perspective. - Biol. Chem. 394: 203-216, 2013.

Semenov, M.A., Stratonovitch, P., Alghabari, F., Gooding, M.J.: Adapting wheat in Europe for climate change. - J. Cereal Sci. 59: 245-256, 2014.

Stirbet, A., Govindjee: On the relation between the Kautsky effect (chlorophyll $a$ fluorescence induction) and Photosystem II: basics and applications of the OJIP fluorescence transient. - J. Photochem. Photobiol. B: Biol. 104: 236-257, 2011.

Stirbet, A., Lazár, D., Kromdijk, J., Govindjee. Chlorophyll $a$ fluorescence induction: can just a one-second measurement be used to quantify abiotic stress responses? Photosynthetica 56: 86-104, 2018.

Strasser R.J., Srivastava A., Govindjee: Polyphasic chlorophyll $a$ fluorescence transient in plants and cyanobacteria. Photochem. Photobiol. 61: 32-42, 1995.

Szklarczyk, D., Morris, J.H., Cook, H., Kuhn, M., Wyder, S., Simonovic, M., Santos, A., Doncheva, N.T., Roth, A., Bork, P., Jensen, L.J., Von Mering C.: The STRING database in 2017: quality-controlled protein-protein association networks, made broadly accessible. - Nucl. Acids Res. 45: D362-D368, 2017.

Voss, I., Sunil, B., Scheibe, R., Raghavendra, A.S.: Emerging concept for the role of photorespiration as an important part of abiotic stress response. - Plant Biol. 15: 713-722, 2013.

Wang, W., Vignani, R., Scali, M., Cresti, M.: A universal and rapid protocol for protein extraction from recalcitrant plant tissues for proteomic analysis. - Electrophoresis 27: 27822786, 2006.

Wang, Y., Zeng, L., Xing, D.: ROS-mediated enhanced transcription of CYP38 promotes the plant tolerance to high light stress by suppressing GTPase activation of PsbO2. Front. Plant Sci. 6: 777, 2015.

Wojtera-Kwiczor, J., Gross, F., Leffers, H.-M., Kang, M., Schneider, M., Scheibe, R.: Transfer of a redox-signal through the cytosol by redox-dependent microcompartmentation of glycolytic enzymes at mitochondria and actin cytoskeleton. - Front. Plant Sci. 3: 284, 2012.

Xu, L., Yu, J., Han, L., Huang, B.: Photosynthetic enzyme activities and gene expression associated with drought tolerance and post-drought recovery in Kentucky bluegrass. - Environ. exp. Bot. 89: 28-35, 2013.

Yadav K.N.S., Semchonok D.A., Nosek L., Kouřil R., Fucile G., Boekema E.J., Eichacker L.A.: Supercomplexes of plant photosystem I with cytochrome b6f, light-harvesting complex II and NDH. Biochim. Biophys. Acta 1858: 12-20, 2017.

Zhao, Z., Assmann, S.M.: The glycolytic enzyme, phosphoglycerate mutase, has critical roles in stomatal movement, vegetative growth, and pollen production in Arabidopsis thaliana. - J. exp. Bot. 62: 5179-5189, 2011.

Zivcak, M., Brestic, M., Olsovska, K., Slamka, P.: Performance index as a sensitive indicator of water stress in Triticum aestivum L. - Plant Soil Environ. 54: 133-139, 2008.

Żurek, G., Rybka, K., Pogrzeba, M., Krzyżak, J., Prokopiuk, K.: Chlorophyll $a$ fluorescence in evaluation of the effect of heavy metal soil contamination on perennial grasses. - PLoS ONE 9: e91475, 2014. 